\title{
THE FINANCIAL LEVERAGE PARADOX. THE CONFUSION SURROUNDING THE LEVERAGE CONCEPT
}

With the help of a simple question juxtaposing geared and ungeared positions, this paper analyzes the inherent ambiguity present in the concept of financial leverage. The answer to this question depends on the way it is (often automatically) understood. It may be perceived as being either about risk, risk reward or a mix of the two. The range of possible answers is virtually unlimited. Unfortunately, most of them, including that given by Miller in his Nobel Prize Lecture, are inconsistent with finance theory. This paradox is represented by the inability to answer the simple question in an unambiguous way, yet its gravity comes from the fact that it is neither noted nor debated in the literature. The confusion surrounding financial performance evaluation, ROE debate or executive pay are just a few examples of how lethal the leverage paradox can be. The leverage-driven financial crisis of recent years shows that the chaos in the literature exemplified by the paradox may easily spill over into real life.

Keywords: financial leverage, gearing, $\mathrm{ROE}$, executive pay, financial risk, risk reward

JEL Classifications: G10, G11, G30, G32

DOI: 10.15611 /aoe.2020.1.12

\section{INTRODUCTION}

"What is the "cost of capital" to a firm in a world in which funds are used to acquire assets whose yields are uncertain?" This is the very first sentence in the seminal paper of Modigliani and Miller in 1958 (p. 261). The question about risk reward was particularly difficult to answer as in those days "no satisfactory explanation has yet been proposed as to what determines the size of the discount rate" (Modigliani and Miller, 1958, p. 262). In fact, Modigliani and Miller attempted to estimate the reward for leverage risk without knowing the answer to the much simpler question about the level of the ungeared cost of equity. The portfolio theory of Markowitz $(1952,1959)$ was still in its infancy, while Capital Asset Pricing Model, or the risk-return trade-off theory, were yet to be formulated by Sharpe (1964), Lintner (1965) and Mossin (1966). Today, in spite of various breakthroughs in the theory of finance, the answers given more than 50 years

\footnotetext{
* Department of Capital Markets, Warsaw School of Economics.
} 
ago are still valid. In short, debt levers risk, this in turn amplifies the required rate of return for owners. Subsequently, the future equity valuation at $T=1$, increases. In the absence of taxes, bankruptcy risk and other frictions, this does not alter the equity valuation at $T=0$ as the higher future returns are merely the compensation for the higher risk.

Although these findings are the very foundations of modern finance theory, with Modigliani, Miller, Markowitz and Sharpe all awarded Nobel Prizes in Economics for their contribution to risk-return trade off, the tendency to concentrate on equity returns alone regardless of the (leverage) risk taken, is still very much alive. The authors believe this is but yet another manifestation of the "conceptual chaos" surrounding the leverage term first diagnosed many decades ago (Dilbeck, 1962). The outbreak of the Global Financial Crisis itself, spurred by excessive leverage, is another. The mistake made by Miller in his Nobel Memorial Prize Lecture, published in 1991 by the Journal of Finance (Miller, 1991) and then reprinted in 2005 in the Journal of Applied Corporate Finance (Miller, 2005), under the telling title Leverage, is probably one of the most spectacular illustrations of this chaos. In his lecture, Miller wrongly identifies the elasticity analysis with the sensitivity analysis prevailing in the works of Markowitz and Sharpe. The mistake was not spotted until 2013 (Berent, 2013).

These authors intend to argue in this paper that the conceptual chaos surrounding leverage may be rooted much deeper than generally believed. This may result from our inability to grasp the very meaning of the "leverage" term, as "leverage" may imply both "debt" as well as "the outcome of using $i t$ ", i.e. both the cause and its effect. The sentence "the company takes leverage" is an example of the first use, "debt leads to leverage" - of the other. As a result, "leverage leads to leverage" is a meaningful statement if properly understood. The scope for the confusion is vast: when a firm is levered it means it is indebted, yet, when we say equity is levered, we acknowledge the fact that the equity holders exert their control over more assets than they actually finance themselves. In the most fundamental sense, the risk as well as the reward for this risk can be levered. As will be shown below, many other things can be levered, or even leveraged (sic!). By formulating a simple question that juxtaposes the geared and ungeared equity positions, the authors attempt to demonstrate that the confusion has semantic roots.

Let us assume the equity value of an ungeared firm increases by $20 \%$. One can then inquire about the corresponding change in the equity value of the otherwise identical but geared company with a known debt-to-equity ratio of, say, 1. In short, the question is: 
How much would the geared equity position with debt-to-equity of 1 change, if the ungeared one increases by $20 \%$ ?

Surprisingly, this simple question has many different answers, depending on how it is understood/interpreted. Interestingly, all the different answers are (algebraically) correct, some are even correct in the context of the finance theory. In fact, some interpretations produce answers only marginally higher than $20 \%$, others - infinitely greater than that. Equal to or less than $20 \%$, or even negative changes, are also feasible. In some interpretations, the answer does not exist at all. The authors illustrate that the question can be interpreted as a question about the risk, the reward for the risk taken, or a mixture of the two. In addition, in most interpretations the dataset available in the question is not sufficiently rich to answer it. Depending on the way the question is understood, different pieces of information are missing. Paradoxically, in some interpretations, knowledge of a debt-to-equity ratio is not necessary at all. In other interpretations, the scale of the ungeared equity change is of little importance. The paradox is dangerous because this plentitude is rarely recognized. It is possible that a person answering the question may adopt a different interpretation than is meant by the person posing it. Moreover, it is feasible that neither realizes this confusion and they continue the debate. Incommensurability in the sense suggested by Feyerabend (2010) could not be better illustrated. The authors brand this phenomenon the leverage paradox and are not aware of any mention of it in the literature.

Given the current scale of leverage world-wide, the problem is by no means theoretical. According to the IMF (Mbave et al., 2018), global debt, at $\$ 164$ trillion in 2016, is at a record high, with the US and China being the biggest borrowers; relative to global GDP, at $225 \%$, it is well above the previous peak in 2009. EU corporate debt surged from $87.8 \%$ of GDP in 2007 to $96.5 \%$ in 2017 (Eurostat, 2019). Indeed, with the general shift to the accommodative and unconventional monetary policies of recent years, the incentives to take on greater financial risks and inflate returns has proved too big to ignore for many market participants. This is reflected in rich equity valuations: price to earnings increased from 13.5 in 2008 to 21.5 in 2017, EV/EBITDA - from 7.8 to 11.2 (Lacalle, 2018). The need to understand leverage has never been more evident.

This paper consists of ten sections. Section 2 summarizes literature on performance evaluation and executive pay - the two most sensitive areas where the scope for mistaking leverage-enhanced results with superior performance is the greatest. The methods used in the paper are explained in 
Section 3. Sections 4 to 8 present five groups of different interpretations of the question posed above and five different answers to it. Section 9 compares the answers, and Section 10 sums up the analysis.

\section{LEVERAGE IN THE PERFORMANCE AND EXECUTIVE PAY LITERATURE}

In performance appraisal and the executive pay debate, the challenge is always to disentangle genuine value creation from risk-enhanced results. This debate was particularly stimulating for the years before the crisis. Rajan (2005) argues this task is particularly difficult for banks. Kim and Santomero (1988) believe that under some conditions return on equity (ROE) may adequately capture a bank's true performance. The obvious drawback of ROE is that it is risk sensitive - the more leverage, the higher, on average, returns on equity. Higher ROE does not necessarily mean better performance. The failure of ROE to discriminate between best and worst performing banks during the crisis is well documented in both academic literature (e.g. Moussu and PetitRomec, 2014) and institutional research (e.g. the European Central Bank, 2010). ROE dispersion around the mean, very small before 2007, drastically increased thereafter as targeting ROE was the prevailing strategy in the banking industry before the crisis and still is today (Pagratis et al, 2014). Haldane et al. (2010) show a bank's operational performance is negatively correlated with leverage: if a bank was poor in terms of operating activity, it attempted to mask it by taking more leverage. Not surprisingly, it was financial leverage that was responsible for decoupling after 2007.

However, the bad press ROE attracted after the crisis seems somewhat misplaced. To show that ROE lacks attachment to liquidity or long term performance, or it depends on leverage, no empirical evidence was required as implicitly implied by e.g. ECB (2010, p. 23). Similarly, the discovery that it is leverage rather than ROE that is "a quite good warning indicator" (ibidem, p. 23) is also obvious. For the same reasons, the expectation that pre-crisis stock returns, just because they are risk sensitive, should predict crisis returns (ibidem, p. 23) is unjustified.

The failure to distinguish between the value creation and valuation at $T=0$ on the one hand, and the analysis of risk induced results generated at $T=1$ on the other can be seen in a prolific body of literature investigating the links between executive compensation and risk-taking. This was particularly clear for banks in the pre-crisis years. If management remuneration is earnings- or equity-linked, either via cash bonuses, option programs or equity stakes, 
taking more risk and higher leverage is rational from the top management perspective (see e.g. Chen et al. 2006; Bai and Elyasiani, 2013; Balachandran et. al, 2011; Hagendorff and Vallascas, 2011; Chesney et al. 2010; DeYoung et al., 2013). Jokivuolle and Keppo (2014) believe financial leverage is the single most important factor that should be looked at in the context of excessive executive remuneration. Boyallian and Ruiz-Verdu (2018) prove that the link between CEO remuneration and risk-taking is particularly strong for highly levered firms. Bolton et al. (2015) explicitly argue executive pay should be linked to debt.

The authors believe the link between executive pay and value creation is blurred and sometimes completely lost not only because the performance of banks is so complicated. Just like the failure to distinguish clearly between risk and risk reward in the performance literature and ROE debate, the inherent barriers to adequately comprehend the issues involved may be embroiled in the semantic confusion surrounding the leverage concept. Countless other examples testify to the fact that the leverage term is more vague than generally believed. One of the most surprising claims ever heard about the leverage is the statement by the European Central Bank that "leverage is used to counter the fall in ROE" (ECB, 2010, p. 19). Indeed, thanks to higher debt which decreases equity, lower earnings may (but need not) lead to higher ROE. More importantly, however, higher debt and lower equity amplify the equity risk and per share value volatility.

\section{RESEARCH METHODS}

Below the authors present a set of standard portfolio and asset pricing theory equations which are methodically used in subsequent sections to answer the question posed above. The authors assume only two types of firm's capital: debt $D$ and equity $E$, where $E_{U}$ and $E_{G}$ are the equity levels of the ungeared and geared firm, respectively. Equity rates of return for the ungeared and geared firm are denoted as $r_{U}$ and $r_{G}$. The expected returns, known also as the cost of ungeared and geared equity, are denoted as $k_{U}$ and $k_{G}$. In this paper, the concepts of "expected" or "required" rate of return, as well as "the cost of capital" are used interchangeably. They also assume that capital structure decisions do not affect operating activity, nor do they influence the firm's valuation. For simplicity, it is also assumed that there are no taxes and bankruptcy, and riskless debt with the cost denoted as $i$. The size of the capital invested at $T=0$ in the ungeared and geared firms is assumed identical: 


$$
E_{U 0}=E_{G 0}+D_{0}=(1+d) \times E_{G 0},
$$

where subscript 0 refers to $T=0$, and $d=D_{0} / E_{G 0}$. At $T=1$, the end of an investment period, the link between $E_{U l}$ and $E_{G I}$ is:

$$
E_{U 1}=E_{G 1}+D_{o} \times(1+i)=E_{G 1} \times\left[1+d \times \frac{(1+i)}{\left(1+r_{G}\right)}\right] .
$$

Equation (3), in the context of the portfolio theory, presents the geared return $r_{G}$ as a weighted average of the long position in the ungeared equity $r_{U}$ and a short one in debt:

$$
r_{G}=(1+d) \times r_{U}-d \times i .
$$

Equation (3) can also be presented in two alternative forms $\left(r_{U} \neq 0\right.$ in (5)):

$$
\begin{gathered}
r_{G}=r_{U}+d \times\left(r_{U}-i\right), \\
r_{G}=r_{U} \times\left[1+\frac{d \times\left(r_{U}-i\right)}{r_{U}}\right] .
\end{gathered}
$$

Each time the ungeared return $r_{U}$ exceeds the cost of debt $i$, the geared return $r_{G}$ exceeds $r_{U}$. Based on (3)-(5), the relationship between $k_{G}$ and $k_{U}$ can be established:

$$
\begin{gathered}
k_{G}=(1+d) \times k_{U}-d \times i, \\
k_{G}=k_{U}+d \times\left(k_{U}-i\right), \\
k_{G}=k_{U} \times\left[1+\frac{d \times\left(k_{U}-i\right)}{k_{U}}\right] .
\end{gathered}
$$

Since $k_{U}>i$ by definition, the cost of the geared equity is higher than that of the ungeared one.

When (3) is applied to any an arbitrary chosen base values of $r_{U B}$ and $r_{G B}$ and subsequently subtracted from (3), one obtains $r_{G}$ as a function of the benchmark value and the deviation from it:

$$
r_{G}=r_{G B}+(1+d) \times\left(r_{U}-r_{U B}\right) .
$$

If $k_{U}$ and $k_{G}$ are treated as base values, equation (9) translates into (10):

$$
r_{G}=k_{G}+(1+d) \times\left(r_{U}-k_{U}\right) .
$$


Last but not least, equation (3) leads to the measures of the risk. The standard deviation of equity returns, $\sigma_{U}$ and $\sigma_{G}$ for the geared and ungeared equity respectively, is a measure of the total risk as proposed by the portfolio theory (Markowitz, 1952). The beta coefficient $\beta_{U}$ and $\beta_{G}$ for the geared and ungeared positions respectively, is the measure of the systematic, undiversifiable risk as proposed by the asset pricing models (see also Hamada, 1972 and Rubinstein, 1973). In the absence of bankruptcy, equation (3) leads to the following:

$$
\begin{gathered}
\sigma_{G}=(1+d) \times \sigma_{U}, \\
\beta_{G}=(1+d) \times \beta_{U} .
\end{gathered}
$$

The increase in both the standard deviation and covariance-driven beta is fully explained by the size of debt taken $d$ and is not affected directly by the cost of debt $i$.

The authors use these standard equations of portfolio and asset pricing theory to answer the question about the geared equity change that corresponds to the ungeared equity value increase.

\section{LEVERAGE AS THE AMPLIFICATION OF RISK}

If the equity value increase invoked in the question refers to the instantaneous value shock experienced now, i.e. $\Delta E / E_{U D}=20 \%$ at $T=0$, then one inquires about the corresponding instantaneous percentage shock to the otherwise identical firm but with debt, i.e. $\Delta E / E_{G 0}$. Let us define the leverage ratio $L_{A}$ to be a ratio of the geared and ungeared percentage value changes at $T=0$. Using equation (1) one finds the following:

$$
L_{A}=\frac{\frac{\Delta E}{E_{G 0}}}{\frac{\Delta E}{E_{U 0}}}=\frac{E_{U 0}}{E_{G 0}}=1+d>1 .
$$

The $20 \%$ upgrade in the ungeared position translates into a $40 \%$ upgrade in the geared one. The change is amplified, or levered, i.e. the leverage ratio $L_{A}$ is greater than 1 .

To determine $L_{A}$ one needs no more information than given in the question. The size of the value shock, $20 \%$ in this example, was immaterial: the change in the geared position is always twice the change in the ungeared one no matter how big/small this change is. With $d=1$, the change in equity 
value is spread over the equity that is half the size compared to the all-equity firm. Consequently, there is too much data in the question.

In this interpretation, the question is all about risk. The leverage ratio $L_{A}=1+d$, known also as an equity multiplier, is a measure of risk consistent with the Modern Portfolio Theory of Markowitz (1952) and the theory of Asset Capital Structure of Sharpe (1964), Lintner (1965) and Mossin (1966), as both the standard deviation of returns and the beta coefficient increase, after the inclusion of debt, by $L_{A}=1+d$ (see equations (11)-(12)).

\section{LEVERAGE AS THE AMPLIFICATION OF RISK REWARD}

Rather than an instantaneous value upgrade now, the value increase invoked in the question can be interpreted as the required return generated between $T=0$ and $T=1$, or the ungeared cost of equity $k_{U}$. The question calls now for the geared cost of equity $k_{G}$ as determined by equations (6) to (8). As $k_{U}$ is by definition greater than $i$, one can conclude that $k_{G}>k_{U}$. Stated differently, the ratio of the two, denoted as a leverage ratio $L_{B}$, is bound to be greater than 1 (see equation (8)).

$$
L_{B}=\frac{k_{G}}{k_{U}}=1+d \times\left[\frac{\left(k_{U}-i\right)}{k_{U}}\right]>1 .
$$

The equity cost of capital gets amplified. This amplification is the acknowledgement of the larger equity risk resulting from debt. The question is no longer about risk but about (required) risk reward. The answer requires the information on $i$ - one needs to know the size of the reward for debt holders. The strength of this amplification (leverage) is lower than that for the risk $\left(L_{B}<L_{A}\right)$ as debt is assumed to be costly $(i>0)$.

Depending on $i$, the answer varies. For example: if $i=10 \%(15 \%)$, then $k_{G}=30 \%(25 \%)$ and $L_{A}=1.5$ (1.25): the $20 \%$ expected increase in the ungeared equity value (from $T=0$ to $T=1$ ) implies an amplified expected increase in the geared equity position of $30 \%(25 \%)$. The cost of equity increases by half (by a quarter), respectively.

To sum up, what previously was understood as a question about risk, is now about risk reward. In the first case, the information on $d$ is sufficient to answer the question, while the size of the analyzed equity change is not necessary. In the latter, on top of $d$, one additionally needs to know $i$. The knowledge of the size of ungeared equity change is indispensable. The strength of the resulting leverages is different. If one understood the question 
as being about risk, the answer is $40 \%$, and if about risk reward, the answer is: "greater than $20 \%$ and less than $40 \%$; yet, unless we know $i$, we really do not know the precise number".

\section{LEVERAGE AS THE "AMPLIFICATION" OF EQUITY RETURNS}

If the ungeared equity position increases between $T=0$ and $T=1$ by $20 \%$ (as in Section 5) but this increase is no longer treated as required, the meaning of the question and the answer to it changes dramatically. The leverage ratio $L_{C}$, now defined as the ratio of two random outcomes of the geared and ungeared positions (see equation (5)):

$$
L_{C}=\frac{r_{G}}{r_{U}}=1+d \times\left[\frac{\left(r_{U}-i\right)}{r_{U}}\right]
$$

does not need to be greater than 1 (as $r_{U}$ may not be greater than $i$ ). The 20\% increase in the ungeared position may not be amplified at all. Different levels of the cost of debt lead to different levels of both $r_{G}$ and $L_{C}$. For example,

- for $i=10 \%, r_{G}=30 \%>20 \%=r_{U}$, and $L_{C}=1.5$;

- for $i=20 \%, r_{G}=20 \%=r_{U}$, and $L_{C}=1$;

- for $i=25 \%, r_{G}=15 \%<20 \%=r_{U}$, and $L_{C}=0.75$;

- for $i=40 \%, r_{G}=0 \%$, and $L_{C}=0$;

- for $i>40 \%, r_{G}<0 \%$, and $L_{C}<0$.

Only in the first case, the amplification, diagnosed by $L_{C}>1$, is spotted (hence the inverted commas in the section title). Lack of information on the $I$ makes the answers impossible.

\section{LEVERAGE AS THE AMPLIFICATION OF DEVIATIONS FROM FUTURE BENCHMARKS}

The question can also be understood to mean:

How much would the geared equity position with $d=1$ change, if the ungeared one increases by $20 \%$ in the future (above a given benchmark)?

In such a case, $20 \%$ is the deviation from $E_{U I B}=E_{U 0} \times\left(1+r_{U B}\right)$, the benchmark equity value in the future (at $T=1$ ). The outperformed benchmark may mean anything: market consensus, management forecast, historic valuation etc. - all meaningful reference points. Based on equation (3), the leverage ratio $L_{D}$ equals: 


$$
\begin{gathered}
L_{D}=\frac{\frac{\Delta E}{\frac{E_{G 1 B}}{E_{U 1 B}}}}{E_{G 0} \times\left(1+r_{G B}\right)}=1+d \times\left[\frac{E_{U 0} \times(1+i)}{\left(1+r_{G B}\right)}\right]= \\
1+d \times\left[\frac{(1+i)}{1+r_{U B}+d \times\left(r_{U B}-i\right)}\right]>1
\end{gathered}
$$

where $r_{U B}$ and $r_{G B}=r_{U B}+d \times\left(r_{U B}-i\right)$ are parts of the future ungeared and geared benchmarks. $L_{D}$ is greater than 1 only because one assumes no bankruptcy, i.e. $r_{G B}>-100 \%$. The geared equity would appreciate by more than $20 \%$. A precise answer requires the information on the benchmarks, for example:

- for $r_{U B}=30 \%$ and $i=10 \%(5 \%)$, the leverage ratio $L_{D}$ equals 1.73 (1.68), and the $20 \%$ increase in the future ungeared equity value (above the benchmark) corresponds to a $35 \%$ (34\%) increase in the geared position;

- for $r_{U B}=20 \%$ and $i=10 \%(5 \%), L_{D}$ is 1.85 (1.78), and the $20 \%$ increase in the ungeared position (above the benchmark) corresponds to a $37 \%(36 \%)$ increase in the geared one;

- for $r_{U B}=10 \%$ and $i=10 \%(5 \%), L_{D}$ is $2.00(1.91)$, and the $20 \%$ increase in the ungeared position (above the benchmark) corresponds to a $40 \%(38 \%)$ increase in the geared one;

- for $r_{U B}=1 \%$ and $i=10 \%(5 \%), L_{D}$ is 2.20 (2.08), and the $20 \%$ increase in the ungeared position (above the benchmark) corresponds to a $44 \%$ (42\%) increase in the geared one;

- for $r_{U B}=-10 \%$ and $i=10 \%(5 \%), L_{D}$ is 2.57 (2.40), and the $20 \%$ increase in the ungeared position (above the benchmark) corresponds to a $51 \%$ $(48 \%)$ increase in the geared one.

Unlike Sections 5 and 6 , but in line with Section 4, the size of the analyzed change $(20 \%$ in the example) does not affect the value of the leverage ratio. Conversely, in line with Sections 5 and 6, but unlike Section 4 , the answer is not possible based on the data given.

The question seems to be about risk, just like in equation (4): taking debt implies higher volatility. However, the fact that $L_{D}$ does not always equal $L_{A}=1+d$, the risk measure derived from the portfolio and asset pricing theories, may seem troublesome. Based on equation (3):

- if $r_{G B}<r_{U B}<i$, then $L_{D}>L_{A}=1+d>1$;

- if $r_{U B}=r_{G B}=i$, then $L_{D}=L_{A}=1+d>1$;

- if $r_{G B}>r_{U B}>i$, then $1+d=L_{A}>L_{D}>1$. 
The actual reason why $L_{D}$ does not equal $L_{A}$ results from the fact that the geared benchmark $E_{G I B}$ does not equal the ungeared one $E_{U I B}$ for most cases except when $r_{U B}=i$.

Some may argue that the required levels of future equity (due to the risk taken), is the most reasonable benchmark to use. The leverage ratio $L_{E}$, a special case of $L_{D}$, is defined as:

$$
\begin{aligned}
& L_{E}=\frac{\frac{\Delta E}{E_{G 1 B}}}{\frac{\Delta E}{E_{U 1 B}}}=\frac{E_{U 0} \times\left(1+k_{U}\right)}{E_{G 0} \times\left(1+k_{G}\right)}=1+d \times\left[\frac{(1+i)}{\left(1+k_{G}\right)}\right]= \\
& 1+d \times\left[\frac{(1+i)}{1+k_{U}+d \times\left(k_{U}-i\right)}\right]>1
\end{aligned}
$$

As $k_{G}>k_{U}>i, L_{E}$ is a downward biased estimator of $L_{A}=1+d$. The information on $i$ is indispensable to determine $k_{G}$, hence the geared benchmark.

To sum up, by focusing on the deviations from the future benchmark, the leverage ratio $L_{D}$ pretends to be the risk measure. However, being dependent on the (arbitrary) choice of the base, it is equally dependent on the benchmark choice as it is dependent on the risk involved. The range of reasonable benchmarks is virtually endless, hence the range of the leverage ratios $L_{D}$ is equally vast. The (leverage) risk, fully determined by debt position, should not change with the change in the benchmark.

Interestingly, if the deviations are measured in percentage points, the answer ceases to depend on the benchmark choice. Any deviation from any arbitrary chosen ungeared base results in $1+d$ greater, i.e. amplified, reaction of the geared equity (see equation (9)).

\section{LEVERAGE AS THE AMPLIFICATION OF THE DEVIATIONS FROM THE EQUITY RETURNS}

Some may understand the question to be phrased in terms of returns:

How much would the geared equity return with $d=1$ change if the ungeared one increases over time (between $T=0$ and $T=1$ ) by $20 \%$ more than assumed?

In such a case, it is the degree of financial leverage index, or DFL, that provides the answer: 


$$
D F L=\frac{r_{U B} \times E_{U 0}}{r_{G B} \times E_{G 0}}=1+d \times\left(\frac{i}{r_{G B}}\right)=1+d \times\left[\frac{i}{r_{U B}+d \times\left(r_{U B}-i\right)}\right],
$$

where $-100 \%<r_{G} \neq 0$. Like $L_{D}$, it requires the information, missing in the question, on both $r_{U B}$ and $i$, crucial to determine the value of benchmarks. Unlike $L_{B}$ and $L_{C}$ it is independent of the size of the equity increase analyzed. Interestingly, as equation (19) shows, $D F L$ does not require the information on the size of debt, or $d$. As the amount of financial costs $\left(i \times D_{0}\right)$ suffices, it is possible that two different levels of debt lead to the same value of $D F L$ :

$$
D F L=\frac{r_{U B} \times E_{U 0}}{r_{G B} \times E_{G 0}}=\frac{r_{U B} \times\left(D_{0}+E_{G 0}\right)}{r_{U B} \times\left(D_{0}+E_{G 0}\right)-i \times D_{0}} .
$$

$D F L$, in its accounting version, is arguably one of the most popular leverage ratios used both in academic finance textbooks and managerial accounting practice. In its most popular interpretation, the index estimates the net profit percentage change that results from a $1 \%$ change in EBIT. Alternatively, $D F L$ measures the percentage change in net profit of the geared company that corresponds to a $1 \%$ change in net profit for an allequity firm. Equation (18) is a market value version of $D F L$ and was explicitly used by Miller in his Nobel Prize Lecture.

The main feature of $D F L$, and a frequently unnoticed one, in the authors opinion, is that it is sensitive to the choice of the benchmark. This leads to serious problems. First, in all cases except when $r_{U B}=r_{G B}, D F L \neq L_{A}$. Then, benchmark-sensitive, $D F L$ may not be even greater than 1 . When $r_{U B}$ is (marginally) higher than $(i \times d) /(1+d), D F L$ is (infinitely) greater than 1 and the $20 \%$ change in the ungeared equity return is accompanied by an (arbitrarily) large change in the geared one, e.g. $100,020 \%$ when $r_{U B}=5.001 \%$. When $r_{U B}<(i \times d) /(1+d)$, DFL is lower than 1 or even (infinitely) negative - the leverage, according to DFL, seems to disappear. For $r_{U B}=(i \times d) /(1+d)$, DFL does not exist at all, the answer to the question does not exist. Algebraically, $D F L$ is lower than $L_{A}=1+d$, on average, so, at best, it is a downward biased estimator of the true risk measure $L_{A}$.

As there are no rules guiding the benchmark choice, with many reasonable candidates available, it is not obvious what a given $D F L$ actually is. It is reasonable to calculate $D F L$ based on the expected levels of return. In such a case, $D F L$, denoted as $D F L^{*}$, is bound to be greater than 1, still, unfortunately, lower than $L_{A}=1+d$ : 


$$
D F L^{*}=\frac{k_{U} \times E_{U 0}}{k_{G} \times E_{G 0}}=1+d \times\left(\frac{i}{k_{G}}\right)=1+d \times\left[\frac{i}{k_{U}+d \times\left(k_{U}-i\right)}\right]>1 .
$$

To conclude, when the change invoked in the question refers to equity returns, the answer is provided by the very popular leverage index $D F L$, yet one that is embroiled in all sorts of controversy. With $D F L$ being benchmark dependent, the link to risk measuring seems to be completely lost. Unfortunately, it is $D F L$ that was chosen by Miller in his Nobel Prize Lecture to illustrate the leverage risk. Miller assumes $d=1, i=10 \%$, and $r_{U B}=20 \%$ and consequently estimates the size of the leverage ratio at 1.33 , exactly the level of $D F L$ as defined by (19)-(20), instead of $L_{A}=2.00$. If he measured the change in returns in percentage points, he would have received the right answer and only then would he be allowed to legitimately refer, as he did, to the portfolio and asset pricing theory by saying: "And this greater variability of prospective rates of return to leveraged shareholders means greater risk, in precisely the sense used by my colleagues here, Harry Markowitz and William Sharpe" (Miller, 1991, p. 482). Having followed the DFL path, he was wrong to associate his result with the work of Markowitz and/or Sharpe.

\section{COMPARISON OF DIFFERENT LEVERAGES - DISCUSSION}

Table 1 lists all the leverage ratios developed above. They all share the same structure, $L=1+d \times$ adjustment, and differ only in the size of the adjustment. Except for $L_{C}$ and $D F L$, all the leverage ratios are necessarily greater than 1, implying a greater change for the geared than for the ungeared equity position. On these grounds alone, the leverage credentials of $L_{C}$ and $D F L$ are doubtful. One should remember: it is $D F L$ that was used by Miller in his Nobel Prize Lecture. In all but one interpretation of the question, the answer is impossible due to insufficient input information. In different interpretations, different pieces of information are missing.

The proliferation of so many different interpretations for what looks like a simple question at an undergraduate level is puzzling. The authors believe that it results from the magnitude of the potential meanings of the phrase: "20\% ungeared equity position increase". This increase can be (automatically) viewed as the deviation from a benchmark at a given moment in time. It can also be interpreted (equally involuntarily, one suspects) as a return generated over time. In the former interpretation, one analyzes the volatility, or the risk, in the latter - the period performance. The leverage ratios $L_{A}, L_{D}, L_{E}, D F L$ and $D F L^{*}$ belong to the risk analysis, $L_{B}$ and $L_{C}-$ to 
Table 1

The leverage ratios resulting from different interpretations of the leverage question

\begin{tabular}{|c|c|c|c|c|c|}
\hline & Definition & $1+d \times$ adjustment & & $\begin{array}{c}\text { Type } \\
\text { of analysis }\end{array}$ & Comment \\
\hline$L_{A}$ & $\frac{E_{U 0}}{E_{G 0}}$ & $1+d \times 1$ & $>1$ & Risk analysis & $\begin{array}{l}\text { Consistent with modern } \\
\text { finance theory }\end{array}$ \\
\hline$L_{B}$ & $\frac{k_{G}}{k_{U}}$ & $1+d \times\left[\frac{\left(k_{U}-i\right)}{k_{U}}\right]$ & $>1$ & $\begin{array}{l}\text { Performance } \\
\text { analysis }\end{array}$ & $\begin{array}{l}\text { Consistent with modern } \\
\text { finance theory } \\
\text { Special case of } L_{C}\end{array}$ \\
\hline$L_{C}$ & $\frac{r_{G}}{r_{U}}$ & $1+d \times\left[\frac{\left(r_{U}-i\right)}{r_{U}}\right]$ & $?$ & $\begin{array}{l}\text { Performance } \\
\text { analysis }\end{array}$ & \\
\hline$L_{D}$ & $\frac{E_{U 0} \times\left(1+r_{U B}\right)}{E_{G 0} \times\left(1+r_{G B}\right)}$ & $1+d \times\left[\frac{(1+i)}{1+r_{U B}+d \times\left(r_{U B}-i\right)}\right]$ & $>1$ & Risk analysis & $\begin{array}{l}\text { Benchmark choice } \\
\text { sensitive }\end{array}$ \\
\hline$L_{E}$ & $\frac{E_{U 0} \times\left(1+k_{U}\right)}{E_{G 0} \times\left(1+k_{G}\right)}$ & $1+d \times\left[\frac{(1+i)}{1+k_{U}+d \times\left(k_{U}-i\right)}\right]$ & $>1$ & Risk analysis & $\begin{array}{l}\text { Benchmark choice } \\
\text { sensitive } \\
\text { Special case of } L_{D}\end{array}$ \\
\hline$D F L$ & $\frac{r_{U B} \times E_{U 0}}{r_{G B} \times E_{G 0}}$ & $1+d \times\left[\frac{i}{r_{U B}+d \times\left(r_{U B}-i\right)}\right]$ & $?$ & Risk analysis & $\begin{array}{l}\text { Benchmark choice } \\
\text { sensitive } \\
\text { Used by Miller in the } \\
\text { Nobel Prize lecture } \\
\end{array}$ \\
\hline$D F L^{*}$ & $\frac{k_{U} \times E_{U 0}}{k_{G} \times E_{G 0}}$ & $1+d \times\left[\frac{i}{k_{U}+d \times\left(k_{U}-i\right)}\right]$ & $>1$ & Risk analysis & $\begin{array}{l}\text { Benchmark choice } \\
\text { sensitive } \\
\text { Special case of } D F L\end{array}$ \\
\hline
\end{tabular}

Source: own research.

the performance analysis. These are two distinct types of analysis, with their distinct meaning and input data requirements. In the performance analysis, the information on the value change ( $20 \%$ in the example) is indispensable. In the risk analysis, it is not (as long as the bankruptcy assumption is not violated, i.e. $r_{G}>-100 \%$ ). As $i$ directly affects the equity returns, i.e. returns for the residual risk bearer (rewarded only after the debt holders are paid up), it is essential within the performance analysis. In the risk analysis, when the risk is measured at $T=0$ (the case of $L_{A}$ ), the knowledge of $i$ is not necessary. However, if the volatility is calculated relative to one of many potential future benchmarks, as it is in the case of $L_{D}, L_{E}, D F L$ and $D F L^{*}$, the information on both $r_{U B}$ - to set the ungeared benchmark, and additionally on debt, $d$ and $i$ - to set the geared one, is vital. In both the risk and performance analyses, there are only two interpretations, one in each case, with their roots in the portfolio and asset pricing theory.

If the original question is to be answered with the input data available, it must be interpreted as the question about the risk. With $d=1$, the immediate answer to the question is: "the geared equity position will change twice the 
change of the ungeared one, or 40\% in the example". According to the portfolio and asset pricing theory: in the presence of debt, both types of risk, the total one, measured by standard deviation of returns, as well as its systematic portion, measured by the beta coefficient, gets amplified by $L_{A}=1+d$. Being the risk analysis, the size of the analyzed change is immaterial. As the benchmarks are known at $T=0$, no information on $i$ is required (if the benchmark was at $T=1$ but the wealth changes were defined in percentage points, making the choice of the benchmark irrelevant, the answer would still be provided by $L_{A}$ ). If $20 \%$ is treated as the required return to compensate for risk taken, the question becomes the inquiry about risk reward. Being in the performance analysis, the question can no longer be answered with the data given. Unless debt is costless, the strength of the risk reward leverage is smaller than that for the risk, i.e. $L_{B}<L_{A}$. If one had the full information on debt, i.e. both on its size $d$ and its cost $i$, one would find, with the help of $L_{B}$, a precise answer. If, for example, $i=10 \%$, the answer is $30 \%$. The above two interpretations, and the corresponding leverage ratios $L_{A}$ and $L_{B}$, constitute the building blocks of the modern portfolio, capital structure and finance theory. The authors explain below that all other interpretations are mixtures of the two and therefore are flawed attempts to describe either the risk or the performance. In contrast to $L_{A}$ and $L_{B}$, all other leverage ratios cannot be determined based on the full information about debt $(d$ and $i$ ). This defect alone questions the reliability of those interpretations. The authors start with the performance analysis and $L_{C}$.

If the ungeared equity change is the period random return $r_{U}=k_{U}+\left(r_{U}-k_{U}\right)$, other than the cost of capital $k_{U}\left(r_{U}-k_{U} \neq 0\right)$, the resulting leverage ratio $L_{C}$ is the combination of the two principle leverages: one that amplifies the cost of capital in line with $L_{B}$, and the other that amplifies the deviation from it $\left(r_{U}\right.$ $k_{U}$ ), in line with $L_{A}$ :

$$
L_{C}=\frac{r_{G}}{r_{U}}=\frac{k_{G}+(1+d) \times\left(r_{U}-k_{U}\right)}{k_{U}+\left(r_{U}-k_{U}\right)}=w_{1} \times L_{B}+w_{2} \times L_{A} .
$$

The weights $w_{1}=k_{U} / r_{U}$ and $w_{2}=\left(r_{U}-k_{U}\right) / r_{U}$, where $w_{1}+w_{2}=1$, need not be greater than zero. Consequently, $L_{C}$, a weighted average of two components greater than 1, need not be greater than 1 itself. The two fundamental leverage processes of finance combined may not produce a leveraged outcome. Being a part of the performance analysis, the information on $i$ is crucial as it determines whether the geared equity position increases by more than $20 \%$, by exactly $20 \%$, by less than $20 \%$, or does not increase at all or even declines. Interestingly, even with $i$ known and the answer available, it 
is still impossible to say how much of the calculated geared position change is due to the required level and how much is due to the deviation from it, i.e. from materialized risk. To sum up, the slight shift in the interpretation of the question, away from the expected levels and $L_{B}$, and towards the random outcomes and $L_{C}$, seems to have completely changed the answer.

Moving to the risk analysis and the volatility around the future benchmarks, all the leverage ratios to be debated now are benchmark sensitive. If the benchmark is defined based on the cost of capital, the leverage ratio $D F L^{*}$ can be shown to be the ratio of $L_{A}$ and $L_{B}$ :

$$
D F L^{*}=\frac{\left(k_{U} \times E_{U 0}\right)}{\left(k_{G} \times E_{G 0}\right)}=\frac{L_{A}}{L_{B}} .
$$

Being a mix of the two principle leverages, $\mathrm{DFL}^{*}$, always greater than 1 , cannot be equal to the true risk measure $L_{A}=1+d$. In fact:

$$
L_{B}>1<D F L^{*}<L_{A}=1+d .
$$

$D F L^{*}$ determines the value of $L_{E}$, which again is also a function of $L_{A}$ and $L_{B}$ :

$$
L_{E}=\frac{E_{U 0}+k_{U} \times E_{U 0}}{E_{G 0}+k_{G} \times E_{G 0}}=v_{1} \times L_{A}+v_{2} \times D F L^{*}=v_{1} \times L_{A}+v_{2} \times \frac{L_{A}}{L_{B}}>1 .
$$

As the weights $v_{I}=E_{G O} / E_{G l B}$ and $v_{2}=\left(k_{G} \times E_{G 0}\right) / E_{G I B}$ are greater than zero, one can conclude:

$$
L_{B}>1<D F L^{*}<L_{E}<L_{A}=1+d .
$$

As for $D F L$, it is both the ratio of $L_{A}$ and $L_{C}$ as well as the weighted average of $D F L^{*}$ and 1 . It can also be phrased in the language of $L_{A}$ and $L_{B}$ :

$$
\begin{gathered}
D F L=\frac{r_{U B} \times E_{U 0}}{r_{G B} \times E_{G 0}}=\frac{L_{A}}{L_{C}}=\frac{k_{U B} \times E_{U 0}+\left(r_{U B}-k_{U}\right) \times E_{U 0}}{k_{G B} \times E_{G 0}+\left(r_{G B}-k_{G}\right) \times E_{G 0}}= \\
x_{1} \times D F L^{*}+x_{2} \times 1=x_{1} \times \frac{L_{A}}{L_{B}}+x_{2} \times 1
\end{gathered},
$$

where $x_{1}=k_{G} / r_{G B}, x_{2}=\left(r_{G B}-k_{G}\right) / r_{G B}$, and $x_{1}+x_{2}=1$. As the weights can be negative, $D F L$ may not be greater than 1 , even if it is a weighted average of 1 and $D F L^{*}>1$. Indeed, depending on the choice of the benchmark, the range of DFL is practically unrestrained. 
As for $L_{D}$, it is a weighted average of $L_{A}$ and $D F L$, hence a function of $L_{A}$ and $L_{C}$ :

$$
L_{D}=\frac{E_{U 0}+r_{U B} \times E_{U 0}}{E_{G 0}+r_{G B} \times E_{G 0}}=z_{1} \times L_{A}+z_{2} \times D F L=z_{1} \times L_{A}+z_{2} \times \frac{L_{A}}{L_{C}}>1,
$$

where $z_{I}=E_{G O} / E_{G I B}$ and $z_{2}=\left(r_{G B} \times E_{G 0}\right) / E_{G I B}$. Although $L_{D}$ is a function of unrestrained DFL, with $z_{2}$ potentially negative, $L_{D}$ is bound to be greater than 1 as one assumes no bankruptcy, i.e $\cdot E_{G I B}>0$.

As $L_{D}, L_{E}, D F L, D F L^{*}$ all belong to the risk analysis, one does not need the information about the initial ungeared equity shift, yet one requires detailed information on the benchmarks instead, hence both $r_{U B}$ (or $k_{U}$ ) and $i$, are not available now. More importantly, being dependent on the arbitrary choice of a benchmark, more than on the risk, they should be viewed as the outcome of a language play in which the choice of the benchmark encodes the information about the risk. With the knowledge of the benchmark one can always decipher this code, yet this procedure is quite unfortunate given the true risk measure is readily available in the form of $L_{A}=1+d$.

\section{CONCLUSIONS}

Confronted with the question about the geared vs. ungeared position change, it is very easy to automatically assign the meaning to it without noticing that the provided answer assumes just one of many different interpretations. Unfortunately, their number is practically unlimited. Although algebraically correct, the answers frequently speak more about the benchmark choice than about the financial situation of a firm. The business rationality of the benchmark choice, e.g. market consensus or management forecast, may blur the lack of leverage theory content of the leverage ratio. As a result, finance (theory and practice) gets populated unnoticed by meaningless leverage objects. In the jungle of so many different leverage meanings, it is no surprise that there is so much confusion in the performance evaluation literature, ROE analysis or executive pay discussion. The challenges posed by the leverage paradox are present virtually in any debate featuring leverage. The leverage paradox is dangerous not only because of the interpretational capacity of the leverage term, but because the paradox is not debated in the literature. The mistake made by the Nobel Prize winner illustrates how easy it is to go astray. The global financial crisis proves that the conceptual chaos surrounding leverage, diagnosed years ago in academic debate, can easily spill over into practice. 


\section{REFERENCES}

Bai, G., Elyasiani, E., Bank Stability and Managerial Compensation, "Journal of Banking and Finance", 37, pp. 799-813, 2013.

Balachandran, S., Kogut, B., Harnal, H., Did Executive Compensation Encourage ExtremeRisktaking in Financial Institutions?, Columbia Business School, Research Paper, 2011.

Berent, T., Financial Leverage: The Case against DFL, "Ekonomista”, 1, pp. 99-126, 2013.

Bolton, P., Mehran, H., Shapiro, J., Executive Compensation and Risk Taking, "Review of Finance", 19, pp. 2139-2181, 2015.

Boyallian, P., Ruiz-Verdú, P., Leverage, CEO Risk-Taking Incentives, and Bank Failure during the 2007-10 Financial Crisis, "Review of Finance", 22, pp. 1763-1805, 2018.

Chen, C. R., Steiner, T. L., Whyte, A. M., Does Stock Option-Based Executive Compensation Induce Risk-taking? An Analysis of the Banking Industry, ,Journal of Banking and Finance”, 30, pp. 915-945, 2006.

Chesney, M., Stromberg, J., Wagner, A., Risk-Taking Incentives, Governance, and Losses in the Financial Crisis, Swiss Finance Institute, Research Paper 10-18, 2010.

DeYoung, R., Peng, E., Yan, M., Executive Compensation and Business Policy Choices at U.S. Commercial Banks, „Journal of Financial and Quantitative Analysis”, 48, pp. 165196, 2013.

Dilbeck, H., A Proposal for Precise Definitions of 'Trading on the Equity' and 'Leverage': Comment, "Journal of Finance", 17, pp. 127-130, 1962.

European Central Bank, Beyond ROE - How to Measure Bank Performance, Appendix to the Report on EU Banking Structures, 2010.

Eurostat, Non-financial corporations - statistics on financial assets and liabilities, 2019.

Feyerabend, P, Against Method, 4th ed. Verso Books, New York, NY, 2010.

Hagendorff, J., Vallascas, F., CEO Pay Incentives and Risk-Taking: Evidence from Bank Acquisitions, "Journal of Corporate Finance",17, pp. 1078-1095, 2011.

Haldane, A., Brennan, S., Madouros, V., What is the Contribution of the Financial Sector: Miracle or Mirage? The Future of Finance, Chapter 2, pp. 87-121, LSE, 2010.

Hamada, R. S., The Effect of a Firm's Capital Structure on the Systematic Risk of Common Stock, "Journal of Finance", 27, pp. 435-452, 1972.

Jokivuolle, E., Keppo, J., Bankers' Compensation: Sprint Swimming in Short Bonus Pools? "Bank of Finland, Research Discussion Paper", 2, 2014.

Kim, D., Santomero, A. M., Risk in Banking and Capital Regulation, "Journal of Finance", 43, pp. 1219-1233, 1988.

Lacalle, D., Are the Effects of Unconventional Monetary Policy on Financial Markets Causing Bubbles?, "Journal of Business Accounting and Finance Perspectives", 1, pp. 95-117, 2018.

Lintner, J., The valuation of risk assets and the selection of risky investments in stock portfolios and capital budgets, "Review of Economics and Statistics", 47, pp. 13-37, 1965.

Markowitz, H., Portfolio Selection, “Journal of Finance”, 7, pp. 77-91, 1952.

Markowitz, H., Portfolio Selection: Efficient Diversification of Investments. John Wiley \& Sons, New York, 1959. 
Mbave, S., Badia, M. M., Chae, K., Global Debt Database: Methodology and Sources, IMF Working Paper, 18/111, pp. 1-52, 2018.

Miller, M. H., Leverage, "Journal of Finance”, vol. 46, pp. 478-488, 1991.

Miller, M. H., Leverage, "Journal of Applied Corporate Finance”, vol. 17, pp. 106-111, 2005.

Modigliani, F., Miller, M. H., The Cost of Capital, Corporate Finance and the Theory of Investment, "American Economic Review", 48, pp. 261-297, 1958.

Mossin, J., Equilibrium in a Capital Asset Market, "Econometrica", 34, pp. 768-783, 1966.

Moussu, C., Petit-Romec, A., ROE in Banks: Myth and Reality, available at SSRN: http://ssrn.com/abstract=2374068; 2014.

Pagratis, S., Karakatsani, E., Louri, H., Bank Leverage and Return on Equity Targeting: Intrinsic Procyclicality of Short-Term Choices, Bank of Greece, Working Paper 189, 2014.

Rajan, R., Has Financial Development Made the World Riskier?, Proceedings of the Jackson Hole Conference organized by the Kansas City Fed, 2005.

Rubinstein, M., A Mean-Variance Synthesis of Corporate Financial Theory, "Journal of Finance", 28, pp. 167-181, 1973.

Sharpe, W. F., Capital Asset Prices - A Theory of Market Equilibrium Under Conditions of Risk, "Journal of Finance", 19, pp. 425-442, 1964.

Received: August 2015, revised: July 2019 